\title{
Mechanical limitations of materials for steel foil based flexible electronics
}

\author{
P.-C. Kuo, V. Chouvardas", J. A. Spirko, K. M. Hatalis and M. Hatalis* \\ Department of Electrical and Computer Engineering, Lehigh University, Bethlehem, \\ Pennsylvania 18015, USA \\ *Department of Informatics, Aristotle University of Thessaloniki, \\ Thessaloniki, Greece
}

\begin{abstract}
This work investigates mechanical limitations of thin film materials on steel foil substrates for flexible electronic applications. A three layer structure consisting of $100 \mu \mathrm{m}$ thick stainless steel foil as the substrate, followed by $1 \mu \mathrm{m}$ thick spin-on-glass passivation layer and $0.3 \mu \mathrm{m}$ thick patterned aluminum interconnect layer on top with varying widths between $10-35 \mu \mathrm{m}$. A collapsing radius test method was adopted for the bending experiment and an elliptical curve fit was used to facilitate the strain measurement. The failure strain of aluminum interconnect layer was detected by monitoring the continuity of the test circuit during the experiment. The corresponding results reveal that the passivation layer cracked at a tensile strain of $0.46 \%$ and delaminated at a compressive strain of $0.68 \%$. The metal interconnect layer ruptured at a tension strain of $1.26 \%$ and delaminated from the substrate at a compressive strain of $1.22 \%$ due to the delamination of the passivation layer underneath.
\end{abstract}

\section{INTRODUCTION}

During the past decade, the attention on large area electronics on flexible substrates has risen sharply. Mechanically flexible electronics have the potential to realize novel applications which will not be limited by the mechanical restrictions imposed by the use of rigid substrates. The main applications targeted are flat panel displays, but other matrix-based electronics such as active sensor arrays are being developed as well. Thin metal foil backplane substrates represent an excellent alternative to polymers or hybrid backplanes (inorganic substrates with polymer/organic coatings) for use as flexible systems since they offer superior chemical resistance in a number of environments and are compatible with high temperature processing $[1,2]$. An important part of any flexible electronics engineering endeavor is quantifying the allowed curvature of a sample and understanding the failure mechanisms to facilitate improvement of the bending properties of the system. When the flexible film-substrate system is bent, tension and compression strain build up in the thin film as well as in the substrate. The failure mode of thin film would be cracking under tension and de-bonding under compression [3]. Although a stiff substrate such as stainless steel might not fracture under bending, any strain of the material which causes plastic deformation of the system may limit its flexible operation. The objective of this study is to characterize the mechanical and electrical properties of thin film materials used in steel foil based flexible electronic systems, such as flexible displays. By analyzing critical strain and failure mode in each of the materials under bending test, we can specify the radius of curvature at which the devices can be operated. 


\section{EXPERIMENT}

The test structure was fabricated on $150 \mathrm{~mm}$ diameter, $100 \mu \mathrm{m}$ thick SUS304 stainless steel foil substrates with surface roughness of $3 \mathrm{~nm}$. The steel foils were spin-coated with $1 \mu \mathrm{m}$ Honeywell Accuglass 512B spin-on-glass (SOG) and cured at $250{ }^{\circ} \mathrm{C}$ on the front for isolation as well as on the back to balance the stress. The $0.3 \mu \mathrm{m}$ aluminum film was sputtered and patterned into a long interconnect by using zigzag structure, showed in Figure 1. Six different line widths from $10 \mu \mathrm{m}$ to $35 \mu \mathrm{m}$ were provided in the structure. The steel wafer was then cut into $100 \mathrm{~mm}$ by $10 \mathrm{~mm}$ rectangular samples of different line widths for the bending experiment. Copper leads were bonded to the aluminum pad by conductive silver glue for resistance monitoring of each sample. The initial resistance of samples were measured and are comparable to theoretical value as in Table 1.

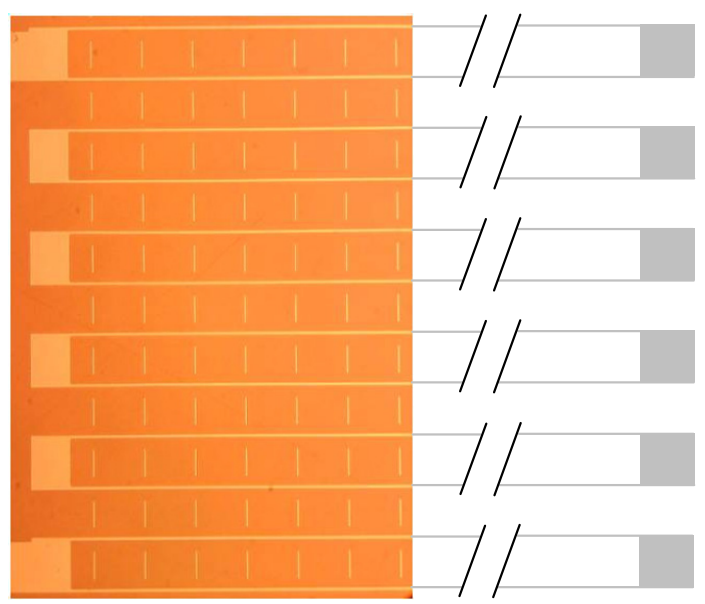

Figure 1. The zigzag interconnect structure of the test pattern

Table 1.Resistance and experiment type of samples

\begin{tabular}{|c|c|c|c|c|l|}
\hline $\begin{array}{c}\text { Width } \\
\text { (um) }\end{array}$ & Length (um) & $\begin{array}{c}\text { Lines } \\
\text { between test } \\
\text { pad }\end{array}$ & $\begin{array}{c}\text { Calculated } \\
\text { resistance (ohm) }\end{array}$ & $\begin{array}{c}\text { Measured } \\
\text { resistance (ohm) }\end{array}$ & \multicolumn{1}{|c|}{ Test Type } \\
\hline 10 & $8.02 \mathrm{E}+04$ & 10 & $1.34 \mathrm{E}+04$ & $1.41 \mathrm{E}+04$ & Compression \\
\hline 15 & $8.02 \mathrm{E}+04$ & 10 & $8.91 \mathrm{E}+03$ & $1.13 \mathrm{E}+04$ & Tension \\
\hline 20 & $8.02 \mathrm{E}+04$ & 10 & $6.68 \mathrm{E}+03$ & $7.40 \mathrm{E}+03$ & Compression \\
\hline 25 & $8.02 \mathrm{E}+04$ & 10 & $5.35 \mathrm{E}+03$ & $5.40 \mathrm{E}+03$ & Tension \\
\hline 30 & $8.02 \mathrm{E}+04$ & 10 & $4.46 \mathrm{E}+03$ & $4.42 \mathrm{E}+03$ & Compression \\
\hline 35 & $8.02 \mathrm{E}+04$ & 10 & $3.82 \mathrm{E}+03$ & $3.60 \mathrm{E}+03$ & Tension \\
\hline
\end{tabular}


The collapsing radius test method is adopted for our experiment because it offers simple setup and testing a function of radius [4]. Since the sample does not conform to a constant radius for the bended area and extracting the true minimum radius of curvature at the center point between the plate is not trivial $[4,5]$, we use a new approach to simplify the radius measurement. By fitting an ellipse to the digital image of bended curve of the sample and measuring its two axis a and b, as shown in Figure 2, the radius of curvature can be calculated as $R=b 2 / a$. With the adjusting $L$ and measuring length of two axis a and $b$, we effectively adjust the radius of curvature R. Knowing the bending radius of curvature, the strain $(\varepsilon)$ of film due to bending is given by $\varepsilon=\mathrm{z} / \mathrm{R}$, where $\mathrm{z}$ is the distance from the neutral surface to the film. In our case the neutral surface is approximately located in the middle of steel foil substrate since the substrate and isolation layer are symmetric and aluminum interconnects are relatively thin and have low pattern density. The microscope was setup to focus on the surface of the sample where the smallest radius was located to detect the failure of material. Interconnect width of 15, 25 and 35 $\mu \mathrm{m}$ were used for outward bending and 10, 20, $30 \mu \mathrm{m}$ were for inward bending.

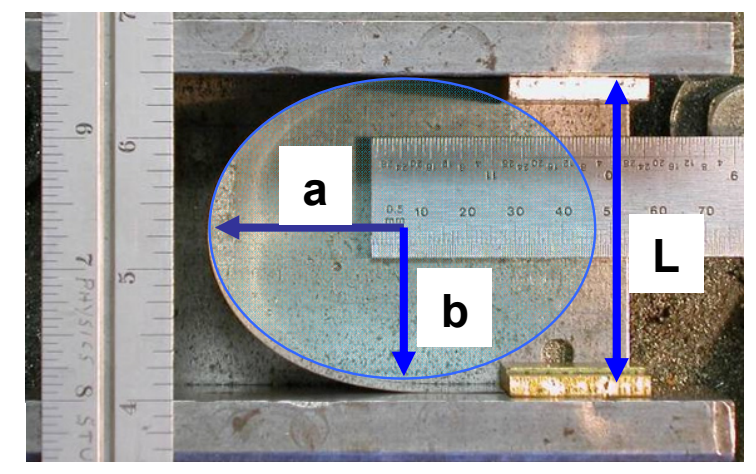

Figure 2.Experiment configuration and radius measurement for collapsing radius test method

\section{RESULT AND DISCUSSION}

\section{Films in tension}

Tension strain builds up in the thin films when the sample is bent outward. When the tension strain increased by $0.46 \%$ the cracks of the isolation layer were first observed between two interconnect and they propagated perpendicular to the strain until reaching the edge of the nearby interconnect, as shown in Figure 3(a). As the tension strain increased from $0.65 \%$ to $0.76 \%$, the cracks increased quickly (Figure 3(b),(c)). The crack density as a function of bending radius is plotted in Figure 4. 


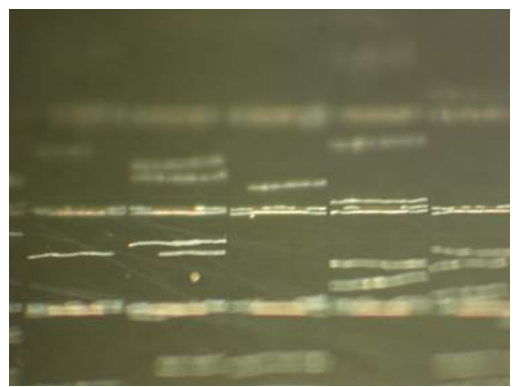

(a)

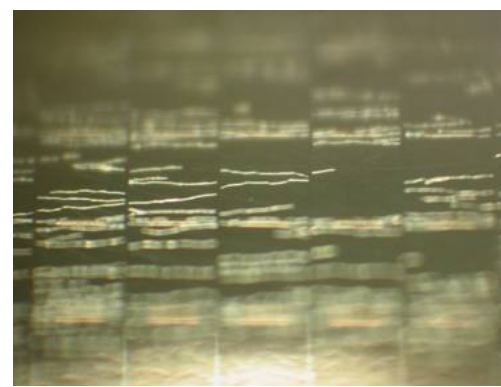

(b)

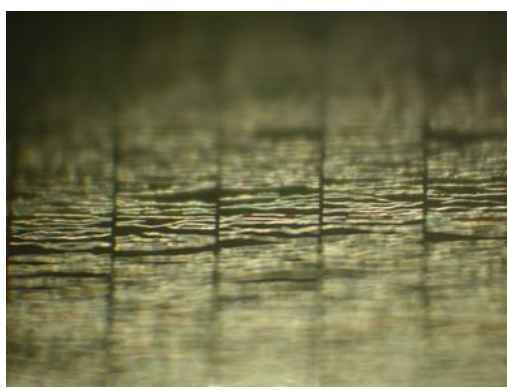

(c)

Figure 3.Cracking of isolation layer as the tension strain increase. (a) strain $=0.46 \%$ (b) strain $=0.65 \%$ (c) strain $=0.76 \%$

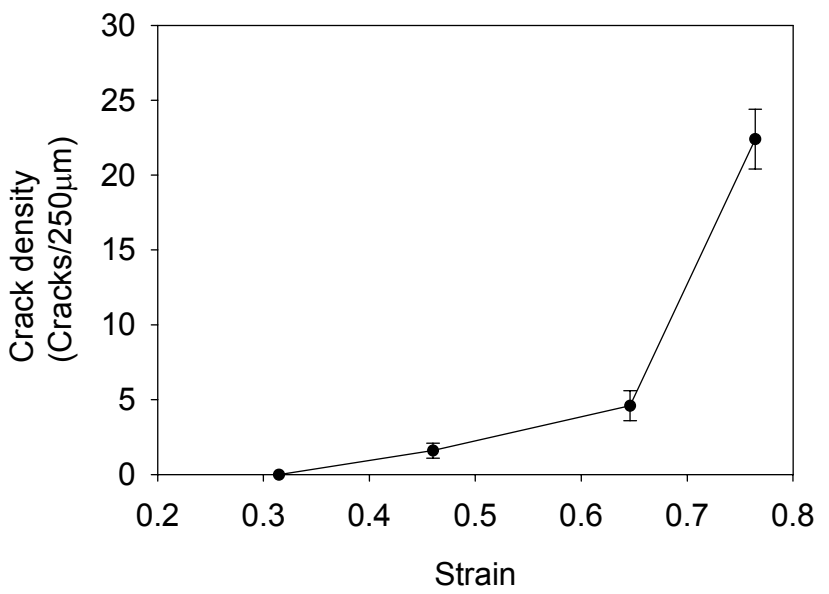

Figure 4.Crack density as a function of strain under compression

As the tension strain increased farther, a failure of the aluminum interconnect line was detected by a discontinuity in the test circuit; this failure occured within the strain range of $1.26 \%$ to $1.52 \%$. As summarized in Table 2 and Figure 5, the wider aluminum interconnect lines could survive larger tension strain; it is interesting to note that the line resistance did not change until the circuit failed. Under the SEM, as shown in Figure 6, we found that the ruptured interconnect line was located directly over a delaminated area of the isolation and that the delaminated SOG was attached to the aluminum line. This suggests that the failure of the aluminum line was due to localized elongation induced by cracking of the isolation layer underneath. Interconnects becomes free-standing once the crack is formed underneath and the failure stains in this experiment were within the range of reported rupture strain of free-standing metal thin film, around $1 \%-2 \%$ [6]. Once the interconnect snaps, the recoil peels part of the SOG isolation layer from the substrate. Since the areas where maximum strains occurred were very small compared to the long interconnects, the resistance change due to local elongation can not be measured. 
Table 2.Strain measurement and resistance monitor data under tension

\begin{tabular}{|c|c|c|c|c|c|c|c|}
\hline Bending type & $\begin{array}{c}\text { Line width } \\
(\mathrm{um})\end{array}$ & $\mathbf{b}(\mathrm{mm})$ & $\mathrm{a}(\mathrm{mm})$ & $\begin{array}{c}\text { Rmin } \\
(\mathrm{mm})\end{array}$ & Strain & $\begin{array}{c}\text { R (ohm) } \\
\text { No strain }\end{array}$ & $\begin{array}{c}\text { R (ohm) } \\
\text { Max strain before } \\
\text { failure }\end{array}$ \\
\hline \multirow{2}{*}{$\begin{array}{c}\text { Face out } \\
\text { (Tension) }\end{array}$} & $\mathbf{1 5}$ & $\mathbf{5 . 4 7}$ & 7.57 & $\mathbf{3 . 9 6 + / - 0 . 3 1}$ & $\mathbf{0 . 0 1 2 6}+/-0.006$ & $\mathbf{1 1 . 2 5 \mathrm { k }}$ & $\mathbf{1 1 . 2 6 \mathrm { k }}$ \\
\cline { 2 - 8 } & $\mathbf{2 5}$ & $\mathbf{5 . 1 6}$ & 7.84 & $\mathbf{3 . 3 9 + / - 0 . 3 0}$ & $\mathbf{0 . 0 1 4 7 + / - 0 . 0 0 7}$ & $\mathbf{5 . 2 4 k}$ & $\mathbf{5 . 2 5 \mathrm { k }}$ \\
\cline { 2 - 8 } & $\mathbf{3 5}$ & 4.69 & $\mathbf{6 . 6 9}$ & $\mathbf{3 . 2 8}+/-0.30$ & $\mathbf{0 . 0 1 5 2 + / - 0 . 0 0 8}$ & $3.51 \mathrm{k}$ & $3.51 \mathrm{k}$ \\
\hline
\end{tabular}

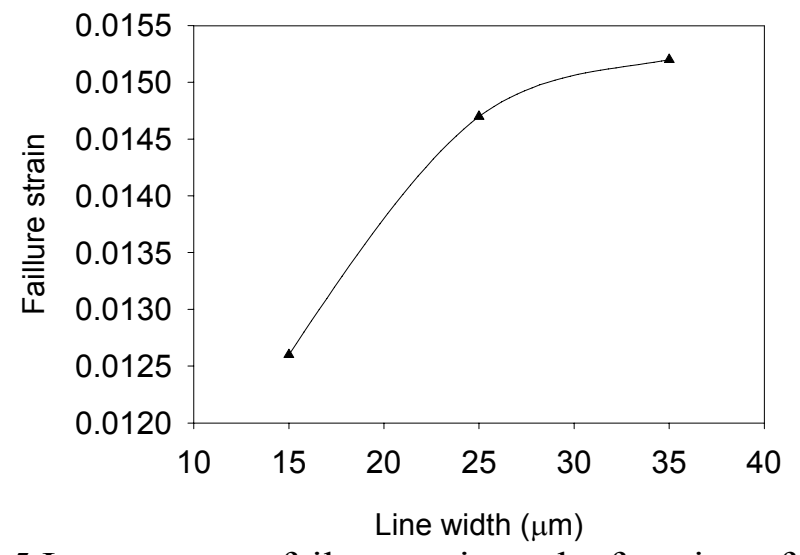

Figure 5.Incterconnect failure strain as the function of line width

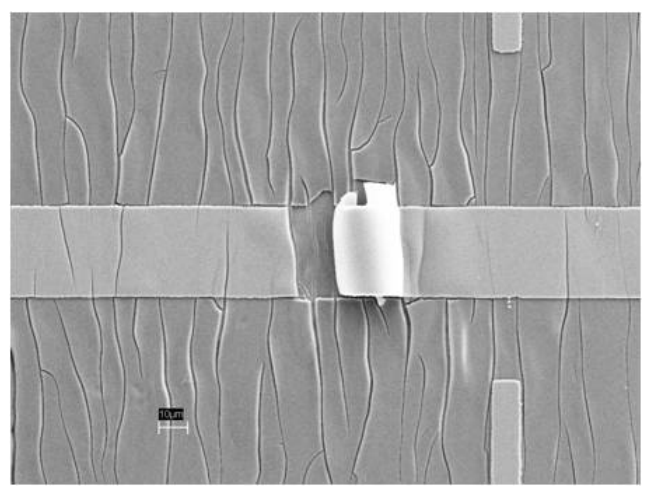

Figure 6.SEM picture of ruptured $35 \mu \mathrm{m}$ interconnect under tension

\section{Films in compression}

When the sample was bent inward, we found that the roughness of the isolation layer increased because of the compressive strain. When the compressive strain was at $0.69 \%$, the isolation layer delaminated from the substrate as shown in Figure 7(a) and the area of delamination increased as the compressive strain increased. As the compressive strain increased to $1.22 \%$ the delaminated areas extended under the interconnect, shown in Figure 7(b), causing the delamination of interconnects from substrate. By the time the compressive strain reached $2.09 \%$, as shown in Figure 7(c), most of the isolation layer had delaminated along with the interconnects on its surface. The SEM picture in Fig. 8 shows the cracked and delaminated 
isolation layer in detail and suggests that the failure mechanism of SOG isolation layer under compression is a combination of delamination, buckling, and cracking [7].

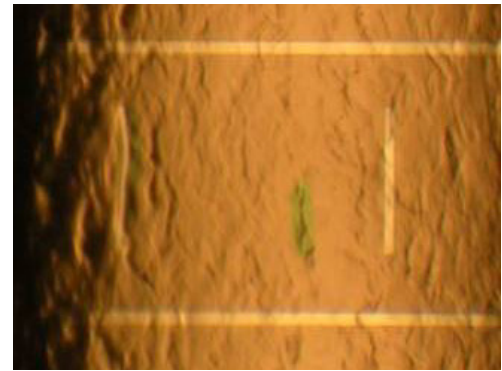

(a)

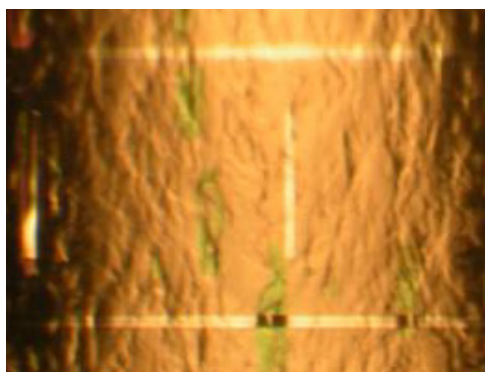

(b)

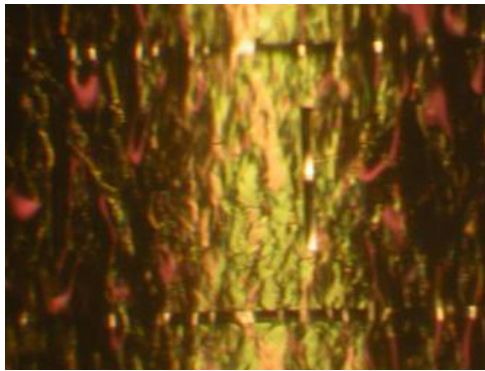

(c)

Figure 7.Delamination of isolation layer and interconnect as the compressive strain increase (a) strain $=0.69 \%$ (b)strain $=1.22 \%$ (c) strain $=2.09 \%$

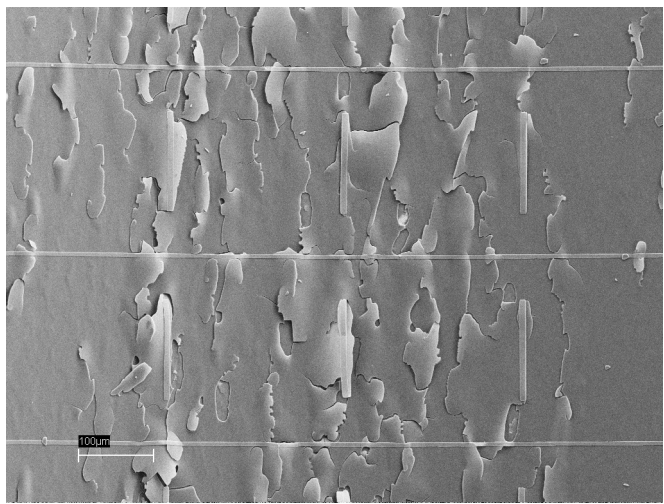

Figure 8.SEM picture of cracked and delaminated isolation layer after compressive strain.

\section{Plastic deformation of stainless steel substrate}

All samples in this experiment were plastically deformed after being released. For SUS304 stainless steel cold rolled strip the Young's modulus and yielding stress are $200 \mathrm{GPa}$ and $260 \mathrm{MPa}$ respectively [8]. Accordingly, the yielding strain is estimated as $0.13 \%$. When compared to the failure strain of the isolation layer, interconnect, and other materials used in flexible electronics such as silicon [9], CVD silicon dioxide[10] and ITO[11] this critical strain of stainless steel is much lower. Therefore the flexibility of steel foil based electronics is limited by the flexibility of steel substrate. Under bending, the relation between minimum elastic bending radius $\mathrm{R}$ and substrate thickness $\mathrm{t}$ is given by $R=\frac{E s}{2 \sigma_{y}} t$, where $\sigma_{y}$ is yielding stress and Es is the Young's modulus of the stainless steel. In this experiment with the substrate thickness of $100 \mu \mathrm{m}$ the minimum elastic bending radius is $38 \mathrm{~mm}$, which is far beyond the failure bending radius of aluminum interconnect $(4.0 \mathrm{~mm})$ and SOG isolation layer $(10.9 \mathrm{~mm})$. Figure 10 shows minimum elastic bending radius of SUS304 as a function of its thickness. It indicates that the flexibility of steel foil based devices can be effectively improved by decreasing the substrate thickness. 


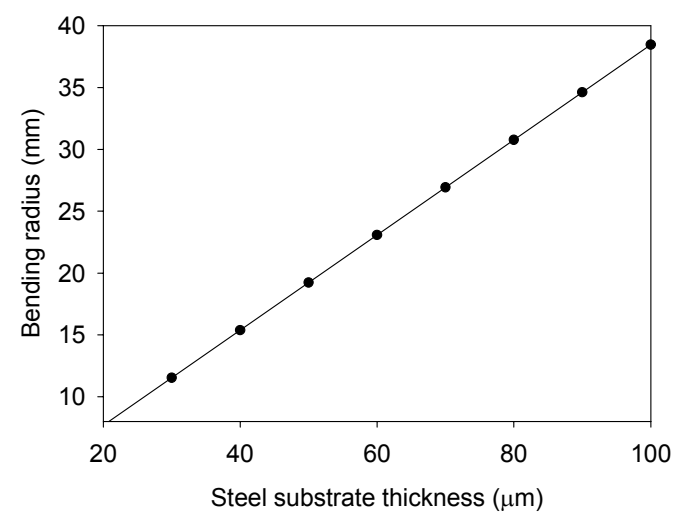

Figure 10. Minimum elastic bending radius as the function of substrate thickness

\section{CONCLUSIONS}

For the steel foil based flexible electronics, the flexibility is limited by the minimum elastic bending radius of the steel substrate with no plastic deformation. This radius is large in comparison with the radius at which the dielectric or metal layers fail. In our $100 \mu \mathrm{m}$ thick steel foil the SOC dielectric layer cracked at an outward bending radius of $10.9 \mathrm{~mm}$ (tension strain = $0.46 \%$ ) and delaminated at an inward bending radius of $7.2 \mathrm{~mm}$ (compression strain $=0.64 \%$ ). The aluminum interconnect on the isolation layer ruptured at an outward bending radius of 3.9 $\mathrm{mm}$ (tension strain $=1.26 \%$ ) and delaminated at an inward bending radius of $4.1 \mathrm{~mm}$ (tension strain of $1.22 \%$ ). In contract, the stainless steel foil was plastically deformed at the relative large bending radius of $38.5 \mathrm{~mm}$ ( $\operatorname{ctrain}=0.13 \%$ ). The failures of aluminum lines were related to the fracture of the isolation layer underneath it, in both tension and compression. The wider lines can withstand higher tension strain when the isolation layer underneath cracks. The flexibility of steel foil based electronics can be effectively improved by using thinner foil substrates.

\section{REFERENCES}

1. T. Afentakis, M. Hatalis, A.Voutsas, and J. Hartzell, IEEE Trans. Electr. Dev., 53, 815 (2006). 2. C.C. Wu, S.D. Theiss, G. Gu, M.H. Lu, J.C. Sturm, S. Wagner, and S.R. Forrest, IEEE Elect. Dev. Lett., 18, 609 (1997).

3. Z. Suo, "Fracture in Thin Films." Encyclopedia of Materials: Science and Technology. second edition, pp. 3290-3296, Elsevier Science, 2001.

4. J. Lewis, S. Grego, B. Chalamala, E. Vick, B.Chalamala and D. Temple, Mat. Res. Soc. Symp. Proc. 814, 1851-1859 (2004)

5. T. Kater, Philips Research Report 2002/812 (2002)

6. T. Li, Z.Y. Huang, Z. Suo, S.P. Lacour, S. Wagner, Appl. Phys.Let. 85, 3435-3437 (2004).

7. G. Crawford, Flexible flat panel displays,(John Wiley \& Sons, Ltd, 2005),p.112

8. Hitoshi Kuwamura,"Research on light-weight stainless steel structure in JAPAN" (2003)

9. S. Greek, F. Ericson, S. Johansson, M. Füresch and A. Rump, J. Micromech. Microeng. 9, 245-251 (1999)

10. D. Gianola and W. Sharpe Jr., Experimental techniques, 28, 23-27(2004)

11. Zhong Chen, Brian Cotterell and Wei Wang, Engineering Fracture Mechanics 69, 597-603 (2002) 